\title{
Development and characterization of MCF7 mammary carcinoma xenografts in a non-immunocompromised rat model
}

\author{
R Dunpall ${ }^{1,2 *}, A R$ Opoku ${ }^{1}$ and N Revaprasadu ${ }^{2}$ \\ ${ }^{1}$ Department of Biochemistry, ${ }^{2}$ Department of Chemistry, University of Zululand, Private Bag X1001, KwaDlangezwa, 3886, \\ South Africa \\ *For correspondence: Email: dunpallrs3@gmail.com
}

Received: 8 May 2016

Revised accepted: 12 September 2016

\begin{abstract}
Purpose: To investigate the development of mammary tumours in female Sprague-dawley rats through a simple subcutaneous injection of human adenocarcinoma breast cells (MCF7) in combination with basement membrane matrix (BME).

Methods: Nine Sprague-Dawley rats were divided into three groups. Group A received no injection, group B was injected with MCF7 cells at a cell density of $7.2 \times 10^{6} / \mathrm{ml}$, and group $C$ was co-injected with MCF7 and BME at $7.2 \times 10^{6} / \mathrm{ml}$ and $3.158 \mathrm{mg} / \mathrm{ml}$, respectively. Tumour growth was observed over a duration of 70 days. Hematological analysis was performed using differential blood cell counts. Histological evaluation was carried out using standard LM techniques and H\&E staining.

Results: At day 35, RBC concentration across all groups was $8.10 \times 10^{6} / \mathrm{mm}^{3}$, whereas by day 70 the range decreased to $(7.64-7.87) \times 10^{6} / \mathrm{mm}^{3}$. White blood cells (WBCs) were within normal range up to day 35, but monocytes and lymphocytes displayed an increase in concentration for group C. Mammary tissues from the thoracic region showed evidence of MCF7 cellular proliferation in both groups $B$ and $C$. Conclusion: This study reveals that BME enhances tumour growth. Further studies are required to investigate optimization strategies for the development of mammary tumours in alternative recipient animal.
\end{abstract}

Keywords: Tumour induction, MCF7, Histopathology, Thoracic mammary gland, Mammary tumour, Basement membrane matrix

Tropical Journal of Pharmaceutical Research is indexed by Science Citation Index (SciSearch), Scopus, International Pharmaceutical Abstract, Chemical Abstracts, Embase, Index Copernicus, EBSCO, African Index Medicus, JournalSeek, Journal Citation Reports/Science Edition, Directory of Open Access Journals (DOAJ), African Journal Online, Bioline International, Open-J-Gate and Pharmacy Abstracts

\section{INTRODUCTION}

The study of cancer however is currently one of the most widely studied and dynamic fields in the forefront of animal research [1,2]. Subsequently the human breast adenocarcinoma adherent cell line (MCF7) and is currently is one of the most predominant cell lines used to study breast cancer cell biology in both, in vitro and in vivo experiments [3]. In addition this cell line is well characterised and therefore a suitable choice for breast cancer research involving tumour growth, hormone and other targeted drug related therapies. The most common in vivo technique within animal models involves the study of tumours [4].

Many researchers demonstrated induction of mammary tumours in rats through the use of chemical carcinogens such as $\mathrm{N}$ methylnitrosurea, dimethylhydrazine and 7, 12dimethylbenz (a) anthracene [5-7]. Other chemical inducers of tumours include the administration of high doses of growth hormones, 
oestrogens or aminofluorene compounds that stimulate the development of mammary tumours [8]. These chemical inducers are toxic and harmful to the animal upon administration and offers low tumour development or growth rates that may take up to 3-4 months before the appearance of an external tumour growth [9]. The development of rapid and efficient growth rate in xenograft techniques is achieved through the application of basement membrane extract (BME) [10-12]. This membrane extract is composed of collagen IV, heparin sulphate proteoglycan, laminin and various other growth factors that work synergistically to promote cell growth and tumour formation [13]. Numerous studies have been conducted to demonstrate the ability of BME to increase uniform tumourigenicity in xenograft applications. Most of these studies were performed on nude mice to induce mammary, pancreatic, prostate, lung and colorectal cancer tumours [10-14]. However these animals are immunocompromised and require specialized breeding, handling and application protocols [11,13].

The current study aimed to demonstrate the tumour inducing ability of BME and MCF7 using Sprague-Dawley rats that have normal functioning immune systems over a period of 70 days.

\section{EXPERIMENTAL}

\section{Ethics statement}

All the animal protocols conformed to the guiding principles of laboratory animal care $(\mathrm{NIH}$ Publication no. 85-93, revised 1985) [15] and were approved by the University of KwaZulu Natal (UKZN) Animal Ethics Committee (approval ref no. 085/14/Animal). All animal research was conducted at the Biomedical Resource Unit, UKZN under direct supervision of the Veterinary staff. The care and use of experimental animals in this study strictly complied with the approved UKZN animal welfare laws, guidelines and policies.

\section{Cell culture}

Modified eagle medium (MEM), phosphate buffered saline (PBS), Trypsin, $100 \times$ pen-strep Fungizone (PSF) and fetal calf serum (FCS) were supplied by Whitehead Scientific. Human breast (MCF7) adenocarcinoma cell lines were purchased from American Type Culture Collection (ATCC) and used in the experiments. This adhesion cell line was grown in MEM culture media containing $10 \%$ FCS and 1- $2 \%$ PSF.

\section{Tumour induction}

The vial containing a concentration of 3.158 $\mathrm{mg} / \mathrm{ml}$ of BME was removed from $-80^{\circ} \mathrm{C}$ storage, placed on ice and allowed to thaw $24 \mathrm{~h}$ prior to tumour induction. Cells that grew as monolayers were trypsinized at passage two and calculated at a total cell density of $7.2 \times 10^{6}$ per $\mathrm{ml}$. Injections were prepared containing equal volumes of MCF7 cells and BME. A 22 gauge needle was used to carefully inject $1 \mathrm{ml}$ of the preparations (MCF7 cells only or MCF7 + BME) subcutaneously into the right thoracic gland of the Sprague-Dawley female rats.

\section{Animals and conditions}

Four-week-old female, specific-pathogen free (SPF) Sprague Dawley rats were acquired from Biomedical Resource Unit, University of KwaZulu Natal. The nine rats were housed and acclimatised for 7 days before starting the experiments. During the acclimatisation and experimental periods, the rats were housed in polycarbonate cages (maximum of 3 rats per cage) in a room with controlled temperature (22.2 $\left.\pm 1.7^{\circ} \mathrm{C}\right)$, humidity $(48.4 \pm 6.0 \%)$, and a $12-\mathrm{h}$ light/dark cycle. The rats were fed rodent pellets and water ad libitum. The rats were divided into three groups (3 rats in each group). Group A was the untreated control animals that received no injection. The animals in group $B$ received subcutaneous injection of human breast adenocarcinoma MCF7 cancer cells at a total cell density of $7.2 \times 10^{6}$ per $\mathrm{ml}$, the animals in group $\mathrm{C}$, received a co-injection of human breast adenocarcinoma MCF7 cancer cells at a total cell density of $7.2 \times 10^{6} / \mathrm{ml}$ and $3.158 \mathrm{mg} / \mathrm{ml} \mathrm{BME}$.

\section{Hematological analysis}

On day 35 of the study, each animal was placed in a warming chamber for a few minutes, followed by blood collection through the lateral tail vein using a 22 gauge needle. The blood (1 $\mathrm{ml}$ ) was collected in heparinized vacutainers. The animal feed was withheld to ensure a $12 \mathrm{~h}$ fasting before necropsy at the conclusion of the study. On day 70 of the study the animals were anesthetised by an overdose of halothane followed by immediate bleeding and exsanguination by cardiac puncture. Then blood was collected in heparinized vacutainers. White and red blood cell counts were analysed using a using a Beckman Coulter DXC600/800.

\section{Histopathological evaluation}

The injection site (mammary tissue) was carefully harvested, weighed and fixed in $10 \%$ formalin 
solution containing neutral phosphate-buffered saline, embedded in paraffin, stained with hematoxylin and eosin, followed by microscopic histological evaluations using light microscopy techniques. For light microscopy (LM) evaluations, the tissue samples were removed from the fixative and dehydrated using a 50 to 96 $\%$ ethanol gradient with the ethanol being subsequently cleared from the tissue using xylene. The tissue was then embedded in paraffin wax using standard procedures. The wax embedded tissues were sliced into $3 \mu \mathrm{m}$ sections using a microtome. The micro-sliced tissue sections were then collected on glass slides, dried and stained with hematoxylin and eosin (H\&E) using standard protocols. The stained sections were examined using a light microscope (LM; Nikon 80i, Kanagawa, Japan) and images were digitally captured using NIS Elements D software and a camera (Nikon U2, Kanagawa, Japan). All tissue evaluations were performed using a minimum of three replicates.

\section{Statistical analysis}

Statistical analysis was performed using GraphPad Prism ${ }^{\circledR}$ Version 5 software. The statistical evaluation included a two-tailed Student's t-test or analysis of variance (ANOVA). The level of statistical significance was set at $p<$ 0.05 . Data was represented as the mean \pm SD $(\mathrm{N}=3)$.

\section{RESULTS}

\section{Animals during tumour induction study}

The animals' behaviour, activity, mobility, alertness, grooming, feed and water consumption was monitored daily over the 70 day study. The animals from all groups appeared healthy, active and alert in addition their food and water consumption observations remained constant throughout the 70 days. The baseline weight of the animals at the start of the study was between 150-160 g (Table 1). The weight of the animals at the end of the study was between 217-227 g, which indicated a $70 \%$ weight increase across all groups over the 70 day period. Weekly examinations were performed to evaluate the presence of a tumour mass. No solid or external growth was observed in group B and $C$. The tissue from the injection site was removed and processed for histopathology analysis.

\section{Hematological analysis of red and white blood cells}

At day $35 \mathrm{RBC}$ concentrations across all groups were $8.10 \times 10^{6} / \mathrm{mm}^{3}$ (Figure $1 \mathrm{~A}$ ), which is within the normal reference range of rat RBC (6.76-9.75 $\left.\times 10^{6} / \mathrm{mm}^{3}\right)$. There was no statistically significant change $(p>0.05)$ in the RBC values from day 35 to 70 as the values obtained on day 70 were between $(7.64-7.87) \times 10^{6} / \mathrm{mm}^{3}$ (Figure $1 \mathrm{~B}$ ). The values obtained for the white blood cells (WBC) ranged between 3.5 and $4 \times 10^{3} / \mathrm{mm}^{3}$ at day 35 (Figure $1 \mathrm{~A}$ ). There was a decrease in concentration to $(1.5-2.07) \times 10^{3} / \mathrm{mm}^{3}$ of WBC observed across all the groups at day 70; however, the decrease was not statistically significant when compared to day 35 . $P$-values obtained were $0.1,0.2$ and 0.2 for group A, B and $C$ respectively. Although there was a decrease in the WBC concentrations, group $C$, retained the highest WBC values at day 70 (Figure 1B).

Differential WBC counts were performed to establish if there were any changes in the individual WBC populations from day 35 to day 70. The values obtained at day 35 were all within reference range for these cell populations (Figure $2 A)$. With the exception of the monocytes and lymphocytes, the results showed a statistically non-significant decrease $(p>0.05)$ in the other cell populations at day 70 . The lymphocytes values increased from 65.23 to $77.67 \%$ and 67.73 to $81.20 \%$ in groups $B$ and $C$ respectively (Figure 2B). Although there was an observable marked increase in these lymphocyte values, those increases were not statistically significant $(p>0.05)$.

Table 1: Animal weight gain and tumour observations during the 70 day study. The data is represented as mean $\pm \operatorname{SD}(n=3)$

\begin{tabular}{lccc}
\hline Variable & $\begin{array}{c}\text { Group A } \\
\text { Untreated control }\end{array}$ & $\begin{array}{c}\text { Group B } \\
\text { MCF7 cells }\end{array}$ & $\begin{array}{c}\text { Group C } \\
\text { MCF7 cells+BME }\end{array}$ \\
\hline Initial body weight $(g)$ & $158 \pm 5.57$ & $161 \pm 7.81$ & $150.67 \pm 6.66$ \\
Final body weight $(g)$ & $225 \pm 10.44$ & $227 \pm 5.51$ & $217 \pm 11.37$ \\
Body weight increase (\%) & $70.40 \pm 5.83$ & $70.90 \pm 5.21$ & $69.44 \pm 4.53$ \\
Tissue removed from tumour & $0.57 \pm 0.16$ & $0.81 \pm 0.09$ & $1.05 \pm 0.14$ \\
site $(g)$ & N/A & No signs of external & No signs of external tumour \\
Clinical observations & & tumour mass & mass \\
& & &
\end{tabular}




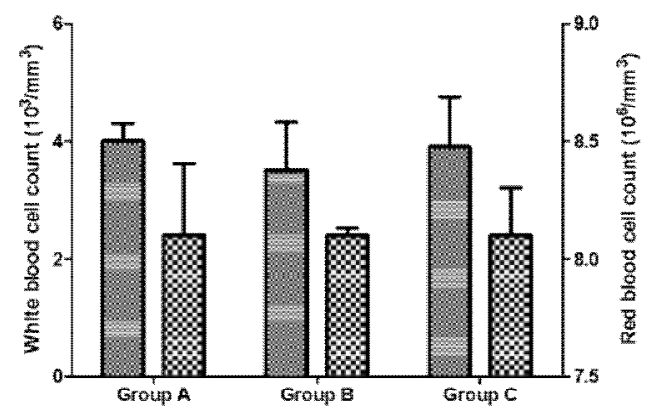

Figure 1: White and red blood cell counts (A) Shows the levels at day 35. (B) Shows levels at day 70. The data is represented as mean $\pm S D$. All values compared to their respective control $(n=3)$

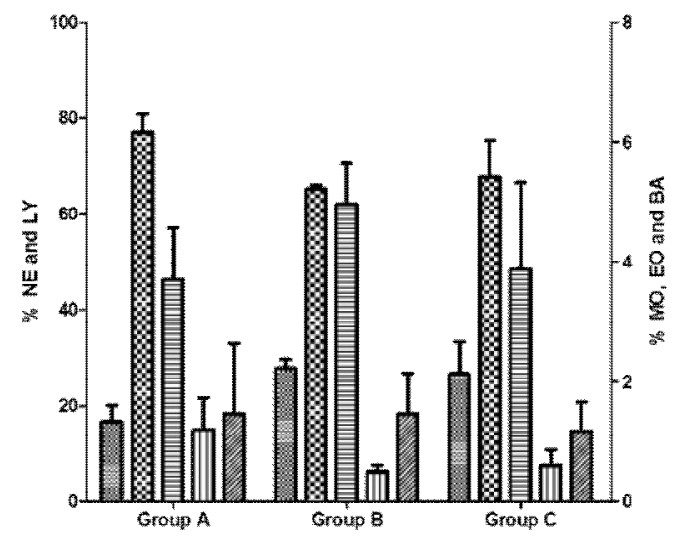

B

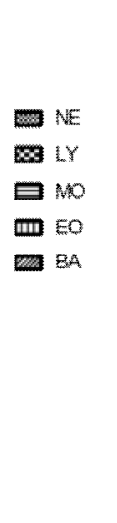

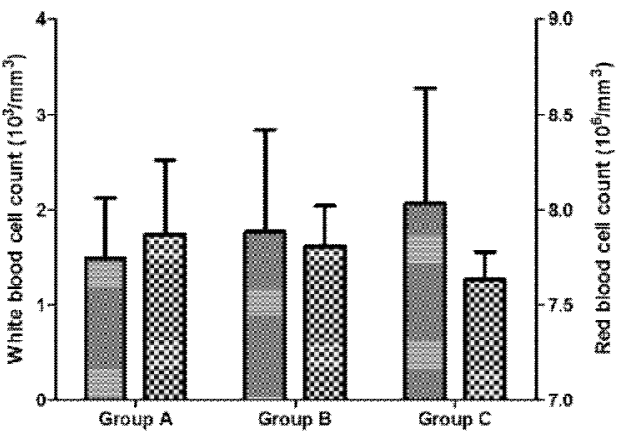

Figure 2: Differential white blood cell counts (A) Shows the percentage of cell populations at day 35. (B) Shows the percentage of cell populations at day 35 . The data is represented as mean \pm SD. All values compared to their respective control $(n=3)$

\section{Histopathology evaluations}

The tissue of interest for histopathology evaluations was obtained from the injection site, situated on the right thoracic glandular region. The photomicrographs from the untreated control group at $10 \times$ magnification (Figure $3 \mathrm{~A}$ ), closely resembles that of normal white adipose tissue found in large closely packed masses between the lobules, with cells having regular morphology and peripherally located, darkly stained nuclei (Figure 3A). For comparative analysis of the tissue sections from group $B$ (Figure $3 B$ ) and $C$ (Figure $3 \mathrm{C}$ ) at $10 \times$ magnification, showed evidence of clusters of MCF7 cells growing within the mammary tissues of treated groups. Although both treated groups exhibited this growth pattern, the photomicrographs of the MCF7 cells + BME treated group showed larger clusters of MCF7 cells inter-dispersed between the adipose cells when compared to the MCF7 treatment (Figure $3 \mathrm{E}$ and Figure $3 \mathrm{~F}$ ). Quantitative analysis of the colony size was established through measuring the surface area occupied by the MCF7 cancer cells from multiple observations of the tissue sections. MCF7treated tissue sections displayed surface areas ranging from 504 to $788 \mu \mathrm{m}^{2}$. MCF7+BME treated tissue sections displayed surface areas ranging from 4693 to $7637 \mu^{2}$ (Figure 3).

\section{DISCUSSION}

The objective of this study was to induce mammary tumours in Sprague-Dawley rats using MCF7 human cancer cells and xenograft techniques. The application of BME was used to increase MCF7 cell growth rate and promote formation of a tumour. An additional aim was to demonstrate the tumour-enhancing ability of BME in rat models. This method of tumour induction has been well studied and highly reported using immune compromised nude mice as the recipient animal model $[16,17]$. 

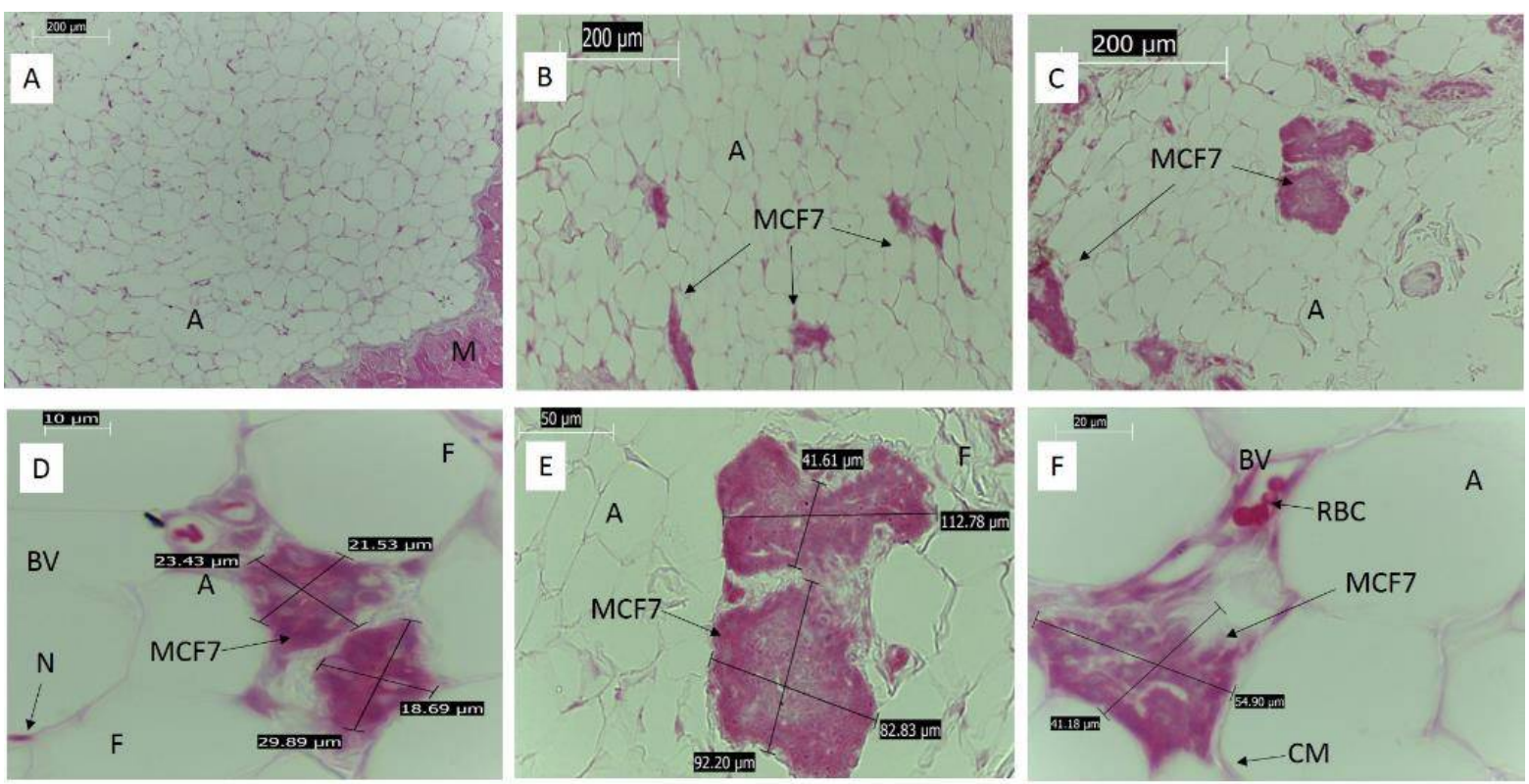

Figure 3: Histopathology of tissue sections from the tumour injection site using light microscopy. (A) Displays the tissue sections from group $A$ at $10 \times$ magnification. (B) Tissue sections from group $B$ at $10 \times$ magnification. (C) Tissue sections from group $C$ at $10 \times$ magnification. (D) Displays the localization of MCF7 cells within the adipose tissue of group B at $40 \times$ magnification. (E) Displays larger clusters of MCF7 cells within the adipose tissue from group $C$ at $40 \times$ magnification $(F)$ shows the growth of MCF7 cells from group $C$, in close proximity of blood supply at $100 \times$ magnification. ( $A=$ adipose cells, $B V=$ blood vessel, $F=$ fibrous interlobular tissue, $N=N u c l e u s$ of adipose cells, $\mathrm{CM}=$ Cell membrane of adipose tissue, $\mathrm{RBC}=$ Red blood cell)

In the current study, nine Sprague-Dawley rats were used. Throughout the 70 day study the animal's maintained normal behaviour, mobility, alertness and feeding patterns. Groups B and C showed no evidence of external tumour growth within the 70 day study. In a similar previous study rat-derived mammary adenocarcinoma LA7 cells were used to induce tumours in Sprague Dawley rats [18]. This technique involved a subcutaneous injection of LA7 cells into the rat-mammary fat pad. The presence of an external tumour was observed at day 30 of the study. Barros et al, showed the presence of mammary tumours in Sprague-Dawley rats after 91 days of induction with 7,12dimethylbenz(a)anthracene [19]. In another study tumour growth induced by the chemical carcinogen $\mathrm{N}$-methyl-N-nitroso urea developed only after 140 - 175 days [7].

Generally blood vasculature is expected to increase as the tumour growth progresses. A developing tumour requires increased blood supply to support the nutrient and oxygen demands of the rapidly growing cancer cells. This process is commonly termed angiogenesis which results in consequent increases in blood cell density. During tumour growth the red blood cell counts are expected to increase. Hematological analyses were performed across all groups at day 35 and 70 to monitor any changes in the red and white blood cell concentrations. In this study the red blood cell counts remained within the normal range as the presence of a tumour mass was not observed in animals from the tumour induced groups $B$ and C. During tumourigenicity, white blood cells play key roles in identifying and destroying cancer cells. The white blood cells are differentiated into many cell types that have specific function within immune responses. Lymphocytes specifically have been reported to induce tumour cell destruction [20]. Abnormally low levels of lymphocytes have been implicated in the negative outcomes associated with cancer patients [21]. Studies show that increased levels of lymphocytes inhibit tumour growth and are also linked to reduced tumour recurrence [22]. The increased percentage of lymphocytes reported in this study could be in response to the introduction of the MCF7 cells in group B and C. The increase in the lymphocyte cell numbers has the potential to inhibit the growth of the injected MCF 7 cells and could therefore be implicated as one of the possible reasons for the restricted growth of these cells observed in the tumour induced groups.

Breast tissue has unique morphology, composed of glandular units arranged in lobules, embedded in a mass of adipose tissue which is subdivided by collagenous and fibrous interlobular tissue [23]. In this study the presence of an external tumour was not observed in animals from group 
B and C, however light microscopy evaluations confirmed that the MCF7 cancer cells localized and grew within the adipose cells that surrounds the lobules of the mammary tissue. The presence of internalized MCF7 cell colonies confirms that the xenograft technique was successful. The tissue morphology from groups $\mathrm{B}$ and $\mathrm{C}$ closely resembles the population density and orientation of MCF7 cells around the adipose tissue as reported in a study by Chang et al, using xenografts in nude mice [24]. Additional reports on breast cancer tissue morphology also support the findings of the current study [25].

Interestingly in the present study, the injected MCF7 cells confined their aggregation and growth very closely to either the cell membranes of the adipose cells or in very close proximity to blood vessels. This can be attributed to the MCF7 cells adhering to areas that have a rich nutrient supply that would enable their successful survival and allow them the ideal conditions to promote tumour growth. In addition the histopathology studies confirmed that the xenograft technique using MCF7 cells and BME was correctly performed. The surface area or colony size that the cancer cells occupied within the MCF7+BME treated (group C) were extensively larger compared to the MCF7 treated (group B).This finding is attributed to the tumour enhancing properties of BME, which promoted higher colony numbers and colony size. The larger clusters of cells observed in group B is attributed to the properties of BME in promoting and stimulating increased growth and adherence of higher cell numbers to the injection site. The technique demonstrated the growth of MCF7 cells in the thoracic region of the mammary gland, however the progression of external tumours in the presence of BME was unsuccessful.

This study also demonstrated that the method of using cancer cells in combination with BME has the potential to induce tumours in rat models however the method may require further optimization. The induction of tumours using animal models that are not immunocompromised is a pivotal aspect of cancer research which has further downstream implications in clinical studies. The challenges in understanding cancer cell interactions and tumour physiology is important in developing effective treatment strategies.

\section{CONCLUSION}

The findings from this study show that MCF7 cells and BME have the potential to induce mammary tumours in Sprague-Dawley rats. The growth of MCF7 cancer cells within the mammary tissues confirms the tumour enhancing properties of BME. Further optimization strategies need to be explored in order to establish a Sprague-Dawley breast cancer animal model that can be used to further develop downstream applications in cancer diagnosis and drug therapeutics.

\section{DECLARATIONS}

\section{Acknowledgement}

The authors wish to thank the University of Zululand and the staff of University of Kwa-Zulu Natal, Biomedical Resource Unit for technical services and support throughout this research project. This work was supported by the Department of Science and Technology (DST) and National Research Foundation (NRF) of South Africa through the DST/NRF South African Research Chairs Initiative (SARCHi) program.

\section{Conflict of Interest}

No conflict of interest associated with this work.

\section{Contribution of Authors}

The authors declare that this work was done by the authors named in this article and all liabilities pertaining to claims relating to the content of this article will be borne by them.

\section{REFERENCES}

1. RDS. The contribution of animal science to the medical revolution: some case histories. Medical Advances and Animal Research. 2007. Research Defense Society: Understanding Animal Research in Medicine and Coalition for Medical Progress (C) 2007

2. Van Der Worp HB, Howells DW, Sena ES, Porritt MJ, Rewell S, O'Collins V, Macleod MR. Can animal models of disease reliably inform human studies? PLoS Med 2010; 7: e1000245.

3. Holliday $D L$, Speirs V. Choosing the right cell line for breast cancer research. Breast Cancer Res 2011; 13: 215.

4. Russo J,Russo IH. Experimentally induced mammary tumors in rats. Breast Cancer Res Tr 1996; 39: 7-20.

5. Roomi MW, Roomi NW, Ivanov $V$, Kalinovsky $T$, Niedzwiecki A, Rath M. Modulation of N-methyl-Nnitrosourea induced mammary tumors in SpragueDawley rats by combination of lysine, proline, arginine, ascorbic acid and green tea extract. Breast Cancer Res 2005; 7: 291-295.

Trop J Pharm Res, October 2016; 15(10): 2090 
6. Perše $M$, Cerar $A$. The dimethylhydrazine induced colorectal tumours in rat-experimental colorectal carcinogenesis. Radiol Oncol 2005; 39: 61-70.

7. Rajmani R, Doley J, Singh $P$, Kumar R, Barathidasan $R$, Kumar $P$, Verma $P$, Tiwari $A$. Induction of mammary gland tumour in rats using $\mathrm{N}$-methyl-N-nitroso urea and their histopathology. Indian J Vet Pathol 2011.

8. Howell J. The chemical induction of breast tumours in the rat: hormonal factors in tumour production. Brit $J$ Cancer 1960; 14: 657.

9. Klaunig JE. Chemical carcinogenesis. Principles of Toxicology: Environmental and Industrial Applications 2014; 259

10. Fridman R, Giaccone G, Kanemoto T, Martin GR, Gazdar $A F$, Mulshine JL. Reconstituted basement membrane (matrigel) and laminin can enhance the tumorigenicity and the drug resistance of small cell lung cancer cell lines. Proc Natl Acad Sci 1990; 87: 6698-6702.

11. Pretlow TG, Delmoro CM, Dilley GG, Spadafora CG, Pretlow TP. Transplantation of human prostatic carcinoma into nude mice in Matrigel. Cancer Res 1991; 51: 3814-3817.

12. Topley $P$, Jenkins $D$, Jessup E, Stables J. Effect of reconstituted basement membrane components on the growth of a panel of human tumour cell lines in nude mice. Brit J Cancer 1993; 67: 953-958.

13. Noël A, De Pauw-Gillet M, Purnell G, Nusgens B, Lapière CM, Foidart J-M. Enhancement of tumorigenicity of human breast adenocarcinoma cells in nude mice by matrigel and fibroblasts. Brit J Cancer 1993; 68: 909915.

14. Bao L, Matsumura Y, Baban D, Sun Y, Tarin D. Effects of inoculation site and Matrigel on growth and metastasis of human breast cancer cells. Brit J Cancer 1994; 70 : 228-232.

15. Health Nlo. Guide for the care and use of laboratory animals (NIH Publication No. 85-23, revised). Bethesda, MD: Author 1985

16. Fridman R, Benton G, Aranoutova I, Kleinman HK, Bonfil $R D$. Increased initiation and growth of tumor cell lines, cancer stem cells and biopsy material in mice using basement membrane matrix protein (Cultrex or Matrigel) co-injection. Nat Protoc 2012; 7: 1138-1144.

17. Benton G, Kleinman HK, George J, Arnaoutova I. Multiple uses of basement membrane-like matrix (BME/Matrigel) in vitro and in vivo with cancer cells. Int J Cancer 2011; 128: 1751-1757.

18. Abbasalipourkabir $R$, Dehghan A, Salehzadeh A, Shamsabadi $F$, Abdullah $R$. Induction of mammary gland tumor in female Sprague-Dawley rats with LA7 cells. Afr J Biotechnol 2010; 9: 4491-4498.

19. Barros ACS, Muranaka ENK, Mori LJ, Pelizon CHT, Iriya K, Giocondo G, Pinotti JA. Induction of experimental mammary carcinogenesis in rats with 7 , 12dimethylbenz (a) anthracene. Rev Hosp Clín 2004; 59: 257-261.

20. Niederhuber JE. Cancer vaccines: the molecular basis for $T$ cell killing of tumor cells. The Oncologist 1997; 2: 280283.

21. Fogar P, Sperti C, Basso D, Sanzari MC, Greco E, Davoli $C$, Navaglia F, Zambon C-F, Pasquali C, Venza E. Decreased total lymphocyte counts in pancreatic cancer: an index of adverse outcome. Pancreas 2006; 32: 22-28.

22. Azab B, Bhatt VR, Phookan J, Murukutla S, Kohn N, Terjanian $T$, Widmann WD. Usefulness of the neutrophil-to-lymphocyte ratio in predicting short-and long-term mortality in breast cancer patients. Ann Surg Oncol 2012; 19: 217-224.

23. Young $B$, Woodford $P$, O'Dowd G. Wheater's functional histology: a text and colour atlas. 2013: Elsevier Health Sciences.

24. Chang Y, Zuka M, Perez-Pinera P, Astudillo A, Mortimer $J$, Berenson JR, Deuel TF. Secretion of pleiotrophin stimulates breast cancer progression through remodeling of the tumor microenvironment. Proc Natl Acad Sci 2007; 104: 10888-10893.

25. Uhlén M, Björling E, Agaton C, Szigyarto CA-K, Amini B, Andersen E, Andersson A-C, Angelidou P, Asplund A, Asplund C. A human protein atlas for normal and cancer tissues based on antibody proteomics. Mol Cell Proteomics 2005; 4: 1920-1932. 